"A critique and potency of socio-technical systems theory: a quest for broadband growth and penetration"

\begin{tabular}{ll} 
AUTHORS & $\begin{array}{l}\text { Karikoga Gorejena } \\
\text { Nehemiah Mavetera } \\
\text { Mthulisi Velempini }\end{array}$ \\
& $\begin{array}{l}\text { Karikoga Gorejena, Nehemiah Mavetera and Mthulisi Velempini (2016). A } \\
\text { critique and potency of socio-technical systems theory: a quest for broadband } \\
\text { growth and penetration . Public and Municipal Finance, 5(2), 7-19. } \\
\text { doi:10.21511/pmf.5(2).2016.01 }\end{array}$ \\
\hline ARTICLE INFO & http://dx.doi.org/10.21511/pmf.5(2).2016.01 \\
\hline DOI & Tuesday, 06 December 2016 \\
\hline RELEASED ON & "Public and Municipal Finance" \\
\hline JOURNAL & LLC “Consulting Publishing Company "Business Perspectives" \\
\hline FOUNDER &
\end{tabular}

NUMBER OF REFERENCES

0

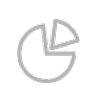

NUMBER OF FIGURES

0

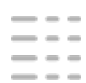

NUMBER OF TABLES

0

(C) The author(s) 2023. This publication is an open access article. 
Karikoga Gorejena (South Africa), Nehemiah Mavetera (South Africa), Mthulisi Velempini (South Africa)

\title{
A critique and potency of socio-technical systems theory: a quest for broadband growth and penetration
}

\begin{abstract}
The purpose of this paper is to appraise the conventional business model of broadband growth and penetration, underscore the shortcomings of such models to introduce a socio-technical based model as a more real and sustainable solution to low broadband uptake. Recent studies on both conventional business model and socio-technical model approach to broadband growth and penetration are reviewed. The socio-technical systems theory (STST) itself is critiqued, and postulates founded by first proponents are questioned for possible refinement. Finally, the potency of the STST approach to broadband is brought to light. The importance and complexities of broadband are discussed. The paper culminates in a proposed framework for broadband growth and penetration which can be used as a decision making tool by policy makers. This resulting proposed framework integrates the conventional business model and the sociotechnical model, as well as the attributes and repercussions of a socio-technical environment.
\end{abstract}

Keywords: socio-technical systems theory, broadband, conventional business model, sustainable, repercussions, attributes.

JEL Classification: 033, 040.

\section{Introduction}

This paper serves to appreciate and to critique recent studies conducted by other researchers on broadband with the objective of filling in the gaps left by these studies. Using previous studies as a foundation, this work intends to make a contribution to the already existing body of knowledge by articulating both the limitations of previous work and introducing a new approach to the question of broadband growth and penetration in general. This new approach is consummated in a proposed framework for broadband growth and penetration.

This review of existing work adopts a thematic approach, where concepts are dealt with according to themes they belong to and, where applicable, a funnel format to concepts is used, where concepts are explained from broad to specific.

The scope of this paper includes studies conducted on broadband growth and penetration in different societies of the world. Value of broadband in various sectors of the economy and society is reviewed as a precursor and motivation for the need of enhanced broadband growth and penetration. Of this review, studies that have looked at broadband frameworks have been considered. However, those studies that have utilized a socio-technical approach to broadband are reviewed separately, as these lead directly to the research topic of this work.

(C) Karikoga Gorejena, Nehemiah Mavetera, Mthulisi Velempini, 2016. Karikoga Gorejena, Ph.D. Candidate, Department of Information Systems, North West University, Mafikeng Campus, South Africa.

Nehemiah Mavetera, Ph.D., Associate Professor of Information Systems, Department of Information Systems, North West University, Mafikeng Campus, South Africa.

Mthulisi Velempini, Ph.D., Doctor of Engineering, Department of Computer Science, University of Limpopo, South Africa.

\section{Broadband}

Scott Peck (2006) argued in the work The Road Less Travelled, Arrow Books, p. 33: “...we are not born with maps; we have to make them, and the making requires effort. The more effort we make to appreciate and perceive reality, the larger and more accurate our maps will be. (...) The biggest problem of map-making is not that we have to start from scratch, but that if our maps are to be accurate we have to continually revise them. The world is constantly changing. (...) The vantage point from which we view the world is (also) constantly and quite rapidly changing. (...) We are daily bombarded with new information as to the nature of reality. If we are to incorporate this information, we must continually revise our maps, and sometimes, when enough new information has accumulated, we must make major revisions [to our map]. The process of making revisions, particularly major revisions, is painful...".

The above passage points directly to philosophy as our perception of reality, which perception is in constant change. Humans are hereby regarded as active agents of this change, making the process a continuous and unending one. It is, however, interesting to note that Peck's assertion has far reaching implications that affect our understanding of socially constructed artefacts such as broadband. The meaning of broadband has evolved with time to such an extent that its definition today is relative to the nation in question. Each country has its own definition of broadband and this definition keeps changing.

Definitions based on data transfer speed are not able to take into account the very fast evolution in technologies and uses. Is a band width of $256 \mathrm{kbit} / \mathrm{s}$ a broadband connection? Should the lower limit be set to $1 \mathrm{Mbit} / \mathrm{s}$ ? There is no definitive answer, as the band width required to run Internet applications is 
continuously increasing and infrastructure standards are also continuously improving to face the growing demand. Such a definition can only be relative to a particular moment in time in a particular country (EU, 2008). The term "broadband" may refer to multiple aspects of the network and services, including: 1) the infrastructure used to deliver services to users; 2) high-speed access to the Internet; and/or 3) the services and applications available via broadband networks, such as Internet protocol television (IPTV) and voice services that may be bundled in a "triple play" package (one in which video, voice and data are provided for in a single access subscription) with broadband Internet access. Further, each country has its own definition of broadband based on speed, typically in Mbit/s or kilobits per second (kbit/s), or based on the types of services and applications that can be used over a broadband network (i.e., functionality). Due to each country's unique needs and history, including economic, geographic and regulatory factors, definitions of broadband vary widely (World Bank, 2012).

In SADC, broadband is defined as always available, multimedia capable interactive network connection with characteristics, as determined by Ministerial Policy and published in Regulations by the Authority from time to time (National Broadband Policy, 2013).

This research uses a working definition of broadband as the provision of telecommunications infrastructure that enables information traffic in a continuous and uninterrupted manner, with sufficient capacity to provide access to data, voice and video applications that are common or socially relevant to users, as determined by the SADC from time to time (World Bank, 2012).

Now that a definition of broadband for this research has been adopted, the following sections looks at attributes of broadband in terms of its value and complexities.

1.1. Broadband as a public good. In most developed and developing countries, broadband and, hence, telecommunication were run by the state or state controlled agencies until the final decades of the 20th century (Picot \& Wernick, 2007). In congruence with these two, the move to have telecommunication controlled by the state was necessitated, among other things, by the need to protect those aspects of telecommunications that are of public interest. Today, even though many telecommunications markets have been privatized and liberalized, government regulatory agencies are still responsible for ensuring that public good issues are provided for. These public good issues include aspects of security, prevention of interference in transmitted signal and safety of the consumers. Public goods differ from other goods in two characteristics: the first is application of non-excludability. That means any member consuming a public good cannot be denied it by another member enjoying the same public good (Olson Jr, 1965). The second characteristic is that a public good is non-rivalry in consumption (Musgrave, 1969). This means, therefore, that public goods should be provided for by the government to guarantee nonrivalry in the market. In some developed countries, broadband forms part of Universal Service Obligation (USO), meaning that it's a right of citizens to have access to it and governments should provide for it. In most countries, however, telecommunications is just a universal service and not necessarily an obligation on the part of government. It is in the potential benefits of broadband and a common thrust to bridge the digital divide which gives broadband its public good character.

It is this inherent quality of broadband, that, in part, requires the need to establish a framework for its growth and penetration that gives better results than have been seen in the recent past, specifically among developing economies. The other obvious, but main motivation for adequate and robust broadband growth and penetration is the fact it has been proven that economic growth of any nation is directly proportional to broadband uptake of that nation. Therefore, sectors of business and public life are directly affected by accessibility to broadband.

1.2. Value and complexities of broadband. According to South African National Broadband Policy (2013), broadband is recognized as a strategic tool for the development of knowledge based economies. Various researches have confirmed that enhanced broadband penetration has desirable effects on economic growth, improved access and delivery of social services apart from bridging the digital divide. All these impacts of broadband result in improved quality of life for citizens and competitiveness of a country. Firth and Mellor (2005) further assert that broadband is at the center of organizations' improved efficiency, faster connectivity, and access to operation-specific applications which usher in new ways of doing business and give birth to new business models.

In considering the value of broadband, research has concentrated on benefits of it singly without taking into account the problems that inherently come with these benefits. There is a number of complexities to understanding the benefits of broadband. One such complexity is that the industry literature has confused benefit with applications, attributes and the activities that these attributes enable. 'Applications include video on demand, gaming, streamed video, and voice over the internet. Attributes include greater speed, always on and the capacity for LANs. The 
activities that these attributes enable include teleworking, e-gaming, e-gambling, e-learning, ehealth, e-commerce, and e-government (Bauer, Gai, Kim, Muth \& Wildman, 2002). Publications of repute and which have contributed immensely to broadband research, but which made this ontological error include ITU on their briefing paper on broadband promotion, according to Reynolds and Sacks (2003).

The other one is that of confusing benefits with activities and gives the notion that it is gross outcome rather net that counts. In so much as broadbandenabled activities bring benefits, they also have negative outcomes which include increased worker isolation and less mentoring in the case of teleworking, financial problems (e-gambling), and displacement of conventional social contacts in general (Katz \& Rice, 2007).

Another complexity is that of cost, if the cost of broadband excludes multiple voices in favor of a monopoly, then, there is a need for constitutional and social considerations (Firth \& Mellor, 2005).

From the above given arguments, it is clear that a high broadband penetration does not equally mean high broadband benefits. Furthermore, according to Crandall and Jackson (2001), calculated revenues expected to be coming from broadband related enterprises do not reflect an adequate measure of benefits of broadband. Lastly, owing to poor planning and veiled understanding of broadband scenarios, the ways by which governments sometimes attempt to use to grow broadband may disrupt the economic and social dynamics (Bauer et al., 2002).

Notwithstanding the highlighted complexities associated with accurately identifying the benefits and, hence, the value of broadband, the following section explains only two of the five main areas of broadband benefits. The other three areas are education, e-government and health. The benefits explained here are Gross Domestic Product (GDP) and cloud computing.

1.3. Broadband and Gross Domestic Product. As frequently cited by a raft of researchers, World Bank study found that low-income to middleincome countries experienced "about a 1.38 percentage point increase in GDP for each 10 percent increase in broadband penetration" between 2000 and 2006 (Qiang \& Rossotto, 2009; Kim, Kelly \& Raja, 2010). This study further found that the development impact of broadband is greater in emerging economies than in high-income countries, which "enjoyed a 1.21 percentage point increase in per capita GDP growth" for each 10 percent increase in broadband penetration. This study also evidenced that broadband has a potentially larger growth effect than other ICTs, including wireline telephony, mobile telephony, and the Internet. There are other studies that confirm the findings of the World Bank such as management consulting firm McKinsey and company which estimated that "a 10 percent increase in broadband household penetration delivers a boost to a country's GDP that ranges from 0.1 percent to 1.4 percent" (Buttkereit et al., 2009). It, therefore, follows that broadband can increase the economy of a country by e-commerce, creating new jobs, developing and attracting new industries and by providing access to local, regional and global markets.

\subsection{Broadband and cloud computing. Cloud} computing generally allows storage, processing and instant access to applications and data remotely via broadband connectivity (World Bank, 2012). This translates into reduced costs of IT infrastructure including hardware, software and technical support. The point to note here is that the benefits of cloud computing are directly the benefits of broadband, because without broadband cloud computing as we know it today would not be possible.

According to Zhang, Cheng and Boutaba (2010), cloud computing has the following other potential benefits:

- reduced need for up-front investment, since cloud computing is typically based on a pay-asyou-go pricing model;

- lower operating costs, since the service provider does not need the provision capacities according to the peak load;

- easy access through a variety of broadbandenabled devices;

- lower business risks and maintenance expenses, since business risks (such as hardware failures) and maintenance costs are shifted to infrastructure providers, which often have better expertise and are better equipped to manage these risks.

There are many other benefits of broadband such as leisure, entertainment, social relations, gaming, green computing, aviation and much more. Governments across the globe have set out ambitious targets for broadband growth and penetration due to the unquestionable value of broadband, as discussed above. Policies are the only tools that governments use to ensure their plans are implemented accurately and consistently. The following sections discuss the concept of policy.

\section{Approaches to broadband growth and pene- tration}

2.1. Conventional economic approach to broadband growth and penetration. Considering section 2 above, it's needless to point out the importance of broadband to a functional and smart information 
society. Consequently, governments across the world have prioritized broadband growth and penetration (Papacharissi \& Zaks, 2006). In view of this, eminent needs to harness the benefits of broadband, Flamm and Chaudhuri (2007) submit that researchers have been having a difficulty understanding the impact of Internet technology and were hampered by both the newness of the field, the absence of data, and the lack of firm and universally agreed upon theoretical structures. Evidently implementation of new technologies either by governments or private enterprises should be informed by research. It, therefore, follows that when research lacks robustness, so do the implementations that draw from it.

Since the advent of broadband and for the past decade, investment in broadband has been viewed as an outlay of equipment to improve technical capabilities (Joo, 2005). Hence, broadband development has, in most cases, been seen and evaluated against the metrics of economic efficiency and physical growth without taking into account the social aspects which are important and fundamental to the question of broadband (Shin \& Jung, 2012). This suggests that broadband should not be understood only in the context of enabling business, but also inclusively with its social implications.

Flamm and Chaudhuri (2007), in their article "An Analysis of the Determinants of Broadband Access", set out to investigate the most determining factors of broadband penetration. The results of their research gave evidence that, indeed, price of broadband services is statistically a significant driver of broadband demand. This was mostly in contrast with the general consensus, as highlighted by the National Telecommunications and Information Administration (NTIA). It suggests that there is a strong correlation between race, age, and levels of income, education, and broadband access decision. This has been supported by GAO (2001), UCLA (2000) and Leigh and Atkinson (2001). One further conclusion which the two arrived at and importantly so is that cost is the obvious limiting factor of broadband demand and both unsubstantiated and sparse: "because high prices for broadband co-exist with low penetration rates does not necessarily imply that the latter is primarily caused by the former", they argue. What is interesting in this work is that after controlling the price, the duo found out that non-price factors exist and affect broadband growth somewhat differently.

It is apparent that even though their work concluded with results that hold true, it was conducted under the bias of conventional economic perspective, hence, it could not articulate the non-price factors nor their impact.
Another study that is of significance was done by the World Bank (2012) in their book "Broadband Strategies Handbook". It is important to note that many researchers on the subject of broadband have used the World Bank model as a reference point. As regards broadband development framework or plan, the World Bank (2012) has highlighted the following pertinent issues.

Governments need to conceptualize broadband as an ecosystem of supply and demand. These two aspects of broadband are interdependent and mutually reinforcing each other. According to Kim, Kelly and Raja (2010), the elements of supply in the broadband ecosystem comprises four levels: international connectivity, domestic backbones, metropolitan connectivity, and local connectivity. The demand side of the ecosystem include components such as services, applications and content. Notably, the supply side is the first determinant of demand, as it pulls it and the demand, in turn, pushes the supply (World Bank, 2012).

A further submission by the World Bank concerns the absorptive capacity of broadband. This is defined as the ability of an organization to identify the value of new external information, assimilate it and, then, to apply it to the organization's benefit. 'This ability is critical to an organization's innovative capabilities, as new technologies are assimilated by organizations to create, improve, and transform business processes, products, and services' (Cohen \& Levinthal, 1990).

According to Duchek (2013), a country's absorptive capacity is determined by the following: the capacity of businesses to create broadband-enabled services and applications and to use these applications and services to make their business processes more productive and efficient, the capacity of citizens to create and use broadband-enabled services and applications to improve their welfare, the capacity of government and other institutions such as hospitals and schools to introduce and accommodate broadband-enabled services to deliver public services more efficiently and transparently to the public. This position is congruent with many other researchers including the World Bank.

The World Bank (2012) further asserts that governments have to play two roles in promoting supply: by making markets more competitive, efficient, accountable and transparent and by ensuring equitable access for all service providers. The role of government should be to facilitate and complement market development instead of substituting government decisions with market forces and public sector investment with private investment. 
According to Pew Internet and American Life Project (2010); EUROSTAT (2009) on inhibitors of broadband adoption by user, the four categories barriers identified are: 1) broadband is not relevant; (2) equipment or service is too expensive; (3) individuals lack training in or are not comfortable using broadband Internet services; and (4) broadband is not available. The role of governments with regards to demand of broadband is to address the above for groups of inhibitors. This research results in having the backing of the World Bank as its basis for supply side policy recommendations.

Lastly, in what is considered from the World Bank (2012) in this research, intervention by governments in form of policy necessary to address challenges of broadband development. According to them, the following policy areas are necessary for broadband growth and penetration: policies that improve access to shared public infrastructures (passive infrastructure) such as conduit, poles, and ducts and to organize civil works as a means to encourage investment, policies that ensure access to rights-of-way or access to national network grid in a fair and nondiscriminatory manner, policies that encourage and promote the installation of open access to passive infrastructure when public works are undertaken and policies that allow municipalities to enter telecommunications markets where market distortion is prevalent. The World Bank suggests also policies that limit municipal participation to basic investments under open access rules to service providers, policies that provide greater and easier access to spectrum and its efficient use.

This research acknowledges the great contribution of the World Bank research specifically on the supply side of broadband. It is worth noting that some policy suggestion for the supply side can inherently also solve some problems of the demand side, for example, open markets encourage competition and, as a result, tend to lower the prices. Policies on quality assurance and accountability of service provider, in turn, create favorable condition for demand of broadband.

However, in developing economies, market forces that are supposed to lower prices in open markets are defeated by monopoly of production and ownership of means of production. As such, prices don't tend to decrease in a monopoly, since there aren't meaningful market forces. The only way prices can easily be made affordable in a monopolized economy is when government imposes tariff controls. This, as well, can scare investors and it becomes a self-defeating pursuit.

Hernandez, Leza and Ballot-Lena (2010) argue that broadband barriers in one country do not necessarily have to be the same as in another country and this is due to different socioeconomic conditions, histories and cultural conditions. On this basis, some of the policy recommendations given by the World Bank can not apply to other people groups. What may be a factor in one country may not be a factor in another country.

Through the concept of absorptive capacity, as explained above, researchers have concluded that organizations need to identify new and external knowledge, assimilate it and use to their advantage. Further to that, the notion is that when technology is new, then, users need to be trained in order to be able to use it. Such a bias leaves society as a passive entity which should conform to the dictates of new technology. Analogically, researchers have concluded that such approach should be used for broadband. This precisely means that broadband has the ability to change societal settings and values. However, Borgman (2000) states that ICT and the social context in which they find themselves are in a relationship of reciprocal shaping. This means society has to speak to broadband the same way as broadband speaks to society, maybe not by the same amount. This is why this research is proposing a new approach to the question of broadband growth and penetration. The conventional economic framework of broadband is critiqued, precisely because of the above mentioned shortcomings.

In his work entitled "Lessons from broadband development in Canada, Japan, Korea and the United States", Frieden (2005) arrived at the following important conclusions considering Canada, Japan and Korea only. Firstly, that broadband thrives when it becomes a national priority. This is a valid observation, as it's supported by many other researchers. Secondly, Frieden (2005) concluded that economic policies do not completely explain why some nations thrive in broadband growth or why they offer faster, cheaper and more convenient broadband than others. This conclusion points to the fact that, apart from economic policies, social policies need to receive as much attention from governments. It is essential to note that the importance of Frieden (2005) work lies in that fact the four countries in question were not performing badly in terms of broadband growth. According to ITU (2005) ranking, Korea was on the first position, Canada and USA on the $6^{\text {th }}$ position. Even though Japan was not in the top 6, but it could have been used as a control. According to his work, the United States government used two funding models to promote broadband with a goal of withdrawing once the critical mass of resources were in hands of private enterprises. These modes are: a top-down approach, where government builds infrastructure and provides incentives for investment in broad- 
band services and a bottom-up "community aggregator model", where government underwrote and funded pilot programs.

There are common recognizable trends among these four nations which could have assisted them to achieve broadband growth. These include regulatory parity that promoted facilities based competition and market entry by operators who might need to access some facilities that were already established, direct underwriting, loans, favorable tax treatment, and other types of financial support for construction of high capacity backbone broadband networks, financial support for research and development (R\&D) and subsidies for buying of ITC equipment, promoting digital literacy and supporting electronic government, education, e-commerce healthcare and other types of ICT-mediated services. In conclusion, the researcher underscores the need for a recurring subsidy and funding mechanism, as opposed to ad hoc funding.

The above observations are quite pertinent, however, these policy measures, as mentioned above, have not yielded the same results in different countries, including these four countries. Besides, policies that might be universally agreed to be working in some countries do not necessarily have to work elsewhere and such policies do not exclude the possibility of other policies of equal importance or even better. This research argues that in so much as economic policies have achieved milestones in promoting broadband growth and penetration, they need to be complemented by social policies, policies that are focused on the human factor, that take into account the uniqueness of societies among which broadband is deployed.

According to ITU (2014), in their latest release of the "State of Broadband" by the end of last year 2014, 2.9 billion people were online, which was about $40 \%$ of the world population. At current growth rate, by 2017, half the world population would be online.

Notwithstanding the above statistics, the same report gives the distribution of Internet user penetration at $32 \%$ for the developing countries, $40 \%$ average and $82 \%$ for the developed countries (ITU, 2014). This shows that the developing world is almost 3 times less connected compared to the developed world. Clearly, the histories of the developed and the developing communities are different, their cultures and social settings are different, their economies are vastly different and these differences have been, even before the advent of broadband. It, therefore, follows that the policies that have yielded good results in developed countries have not yielded good results among developing countries. Therefore, the cause for the difference can only lay in the differences between these groups of countries, as outlined above. Cardinally, these differences are socioeconomic in nature. This necessitates the development of social policies to complement the economic ones largely at play today.

With holes having been poked in the economic model as argued above, with other researchers even of economic models identifying non uniformity in societies necessitating differential application of economic policies and with even others spotting non price factors of broadband growth and penetration, it becomes necessary to explore the social aspects of broadband. In view of this, the following section addresses the sociotechnical approach to broadband.

2.2. Socio-technical approach to broadband growth and penetration. Congruent with Shin and Jung (2012), social and cultural considerations are of paramount importance if any broadband system is to succeed. Joo (2010), Preston, Cawley \& Metykova (2007) concur with this assertion. In line with them, broadband should be used as a vehicle to bridging different cultures by addressing various social issues and problems, therefore, a framework for such action is important. This research uses a socio-technical approach to couch the question of broadband growth and penetration. The sociotechnical approach is based on socio-technical systems theory.

The paucity of comprehensive generalizable scholarly material on socio-technical approach to broadband is notable. However, some researchers like Oni and Papazafeiropoulou (2008), in their work "A socio-technical approach to broadband diffusion by SMEs", discovered perception gaps among groups responsible for broadband diffusion and attributed those gaps to slow uptake of broadband among SMEs. The researcher reckons that perception is key to engaging in any activity. Therefore, in essence, the contribution of the research mentioned above would be to call for training and campaign. This complements the economic approach's call for training at workplaces.

Shin (2009), in his work "A socio-technical framework for cyber-infrastructure design implication for Korean cyber-infrastructure vision", did a tremendous work in applying a socio-technical approach in analyzing how cyber infrastructure (CI) will evolve and stabilize in the cyber space in Korea. His work also investigated the complex relationships that exist between social and technical aspects of CI owing to the evolving nature, diversity and interface which constitute expected of in the next generation networks. The work also describes the challenges asso- 
ciated with development and deployment of CI in Korea. Some notable conclusions from this work are that Korean people's involvement in information ecology depends largely on the motivation people have and their attitude towards CI. There is a tendency in Korea of thinking that the impact of CI on culture and society are just side benefit of efforts targeted at benefiting scientist. CI planners have a top-down approach and do not involve all stake holders. There is a need for strategic IT planners to in-cooperate social issues on technical aspects and have information campaign of overall national strategy among other conclusions. Shin (2009)'s work brings a great contribution to the socio-technical approach and this research borrowed a lot from it.

Another equally masterpiece of research was done by Trkman et al. (2008) entitled "Factors of broadband development and the design of a strategic policy framework". Their research was aimed at determining factors that affect broadband development in EU countries using Exploratory Factor Analysis. The factors were identified and strategic policy framework was developed. This research has enhanced this framework as part of its overall proposed framework. Many other researches have been conducted applying the socio-technical approach, however, their aims and conclusions were not that different from the ones this research has just cited: works like "Evaluating Factors Affecting Broadband Adoption in Kenya" by Mugeni et al. (2012), "Broadband and mobile opportunities: a sociotechnical perspective" by Sawyer et al. (2003).

What is notable in most of these works it that the conclusions they reached are country or region specific and, hence, their recommendations are location based. Nonetheless, the above researches, except for Trkman and others, do not come up with a framework structure which, although it can be used to in specific cases, but remains generally applicable to any case in different context. Such an adaptable framework can be a useful tool for policy makers.

Another major shortcoming in most of these researches is the fact that frameworks suggested by researchers, though very useful, are mainly concerned with micro level application which is mostly at organizational level. They lack a national and international scope, they falter at macro level.

This research contends that, in order that a researcher understands and applies socio-technical approach to any phenomenon, the researcher has to, first, fully understand the concept of socio-technical systems theory. For that to hold true, one has to understand where this theory inherits from. Notwithstanding the modifications one can propose to the original theory, it still remains necessary to fully understand the mind of the first proponents of the parent theory.
The following section takes the reader on a journey that culminates with the current socio-technical systems theory under discussion.

2.2.1. Levels of socio-technical systems. According to Trist (1981), socio-technical studies can be done in three broad levels which range from micro to macro levels, each of which is interrelated. The following is the description of the three levels by Trist:

1. Primary work systems. These are the systems which carry out the set of activities involved in an identifiable and bounded subsystem of a whole organization such as a line department or service unit (Miller, 1959). They may consist of a single face-to-face group or a number of such groups together with support and specialist personnel and representatives of management plus the relevant equipment and other resources. They have a recognized purpose which unifies the people and the activities.

2. Whole organization systems. At one limit, these would be plants or equivalent selfstanding workplaces. At the other, they would be entire corporations or public agencies. They persist by maintaining a steady state with their environment.

3. Macro-social systems. These include systems in communities and industrial sectors and institutions operating at the overall level of a society. They constitute what I have called 'domains' (Trist, 1976a, 1979a). One may regard media as socio-technical systems. McLuhan (1964) has shown that the technical nature of different media has far-reaching effects on users. The same applies to architectural forms and the infrastructure of the built-environment. Although these are not organizations, they are socio-technical phenomena. They are media in Heider's (1942), as well as McLuhan's sense.

This research focuses on the macro-social systems in the sense that it targets an overall level of society, specifically, the SADC community. However, in reality, this research transcends all the three levels mentioned given the fact that it proposes a framework as its outcome. This framework is applicable to both the micro-level of systems, as well as the macro-level. The basic design principles of sociotechnical systems remain the same in spite of the level of the system in question. These principles can easily cascade to the micro systems units, if they are entrenched in policies at macro level which, in turn, are meant to inform organizational policies.

Congruent with Trist (1981), as history of society unfolds people change in values and their expectations concerning work roles change as well. This changes the parameters of socio-technical design, 
even though the principles may remain the same. Conversely, changes in technology change people's values and all other aspects of their live. Therefore, socio-technical phenomena are contextual, requiring the need for inquiry and survey before designs can be done in earnest, especially at macro-levels.

\subsubsection{The concept of socio-technical systems theory} (STST). Socio-technical systems theory is one such systems approach that "focuses on the interdependencies between and among people, technology and environment" (Cummings, 1994). This approach seeks to optimize both the social and technical elements of an organization or work unit.

Socio-technical system theory is based on the premises that an organization or a work unit is an intrinsic combination of social and technical elements and that it is open to its environment (Trist, Higgin, Murray \& Pollack, 1963). Owing to the fact that both "social and technical elements must work together to accomplish tasks, work systems produce both physical products and social/psychological outcomes" (Appelbaum, 1997). In light of this, the main agenda that answers to STST is to design work in such a manner that the two parts yield positive outcomes. This is called joint optimization, according to Appelbaum (1997). This approach to business is in contrast with traditional methods of doing business. In the traditional approach, the technical elements are designed first, and, then, fit people to it. This method has often led to mediocre performances at high social costs.

Socio-technical approach has had a wide spread application due to its generality and so has the capacity to be "adopted with ease to almost any organizational situation... and remains open to continual improvement and revision" (Hackman \& Oldham, 1980).

The coordination between human and technical activities can only be successful and meaningful if one system is supportive of the other (Hackman \& Oldham, 1980). Owing to the interdependence of all systems, a change in one systems affects inevitably the other systems (Harvey \& Brown, 1992). The social subsystem of the overall system targets at coming up with a work design that answers to the psychological needs of the employee. It also gives the worker a sense of belonging and responsibility for the outcome of the work itself. This is according to Cummings (1994).

One other indispensable fact about socio-technical systems is that they are open systems (Emery \& Trist, 1965). This means that the system is open to the environment and, therefore, changes in the environment affect the system goals. These changes in the environment should be accommodated by the system in the least disruptive manner possible (Appelbaum, 1997).

In conclusion to this section, it is expedient to point out that technological improvements on their own do not necessarily mean high productivity or high performances. Inherent to technological systems is the social system and the latter needs to be supportive of its members (Cummings, 1997). In line with the thinking of Cummings (1981), the work environment needs to have semi-autonomous work groups to enhance productivity sense of ownership among workers is a socio-technical environment. Given the many aspects of socio-technical systems, it is, therefore, necessary to encapsulate the aspects of it in principles. Cherns (1986) gave principles of socio-technical system design as follows:

1. Overall productivity is directly related to the system's accurate analysis of social and technical needs and requirements.

2. An accurate analysis of the social and technical needs usually leads to work designs with the following characteristics:

- Minimal critical specification of rules - this principle has two aspects, negative and positive. The negative simply states that no more should be specified than is absolutely essential; the positive requires that we identify what is critical to overall success. In practice, this means the work design should be precise about what has to be done, but not how to do it. The use of rules, policies and predefined procedures is kept to the absolute minimum.

- Variance control - variances, or deviations from the ideal process, should be controlled at the point where they originate. This recognizes each individual as the first line of defense for his or her respective core tasks and the manager as the first line of defense for most boundary-related tasks.

- Multi-skills - each member of the system should be skilled in more than one function so that the work system becomes more flexible and adaptive. This allows a function to be performed in many ways utilizing different people.

- Boundary location - roles that are interdependent should be within the same departmental boundaries. Interdependence may be a function of both knowledge and expertise. Boundaries are usually drawn on the basis of one or more of three criteria: technology, territory or time.

- Information flow - information systems should be designed primarily to provide information to the point of action and problem solving. This is in contrast to most systems, which provide in- 
formation based on hierarchical channels.

- Support congruence - the social system should be designed to reinforce the behaviors intended by the new structure. Rewards, hiring practices, departmental structures, training systems, and so on, all need to be congruent with the basic work design and work group structures.

- Design and human values - the design should achieve high results by providing a high quality of work life to fulfil individual needs. This is the very heart of STS theory. Superior results come from the joint optimization of individual and organizational needs.

On the other hand, Trist (1981) gave the following principles for socio-technical designs:

1. The work system, which comprised a set of activities that made up a functioning whole, now became the basic unit rather than the single jobs into which it was decomposable.

2. Correspondingly, the work group became central rather than the individual job-holder.

3. Internal regulation of the system by the group was, thus, rendered possible rather than the external regulation of individuals by supervisors.

4. A design principle based on the redundancy of functions rather than the redundancy of parts (Emery, 1967) characterized the underlying organizational philosophy which tended to develop multiple skills in the individual and immensely increase the response repertoire of the group.

5. This principle valued the discretionary rather than the prescribed part of work roles.

6. It treated the individual as complementary to the machine rather than as an extension of it (Jordan, 1963).

7. It was variety-increasing for both the individual and the organization rather than variety decreasing in the bureaucratic mode.

As the reader can observe, the above two sets of principles are almost identical save for variance control, and boundary location mentioned by Cherns (1992), but not mentioned by Trist (1981). In that context, the two sets are complementary to each other. However, one major shortcoming this research finds in these principles is the fact that they reduce the social aspect of the whole system to high quality of work life, as pointed by Cherns (1992). This research proposes that true social value is unique and is far more than a high remuneration at work or just a cordial interrelationship in a work community. Important as this may be, but the social element needs to incorporate the history or people, the culture, the demographics and many other societal factors, as outlined in proposed framework. These factors should be as a result of research and consultation with locals or enshrined in a national policy. So the point is that the macro-level application of STST needs to find its deliberate reduction to the micro-level application at company levels.

The thrust of Cherns (1992) and Trist (1981) is that technology shapes the society, this research contends that the shaping should be reciprocal such that technological advancement needs also to follow the dictates of social values.

The two agree that the environment element of the STST is made up of the competitors and the market mainly, the researcher proposes that society is a major environment component and so is the national regulatory framework (Kelly \& Raja, 2010). Organizational and company policies should answer to national agenda and, hence, should be enforced by national policy.

Appelbaum (1997) states that it is a common element among organizations to remain viable. Therefore, organizations are naturally driven by making profit. However, national agendas do not always lead to immediate profits, if any at all. For this cause, some policies have to be monitored at national level lest organization will simply not implement them.

\subsubsection{STST application to broadband. According to} Sawyer, Allen and Lee (2003) perspective and with respect to broadband, STST is a solid framework for investigating the complex interrelationships of technical and social processes, given that the framework should include technological and social details of large-scale ICT projects.

From this perspective, Borgman (2000) conceptualized broadband as a socio-technical system. Sawyer et al. (2003) investigated broadband and mobile infrastructures from a socio-technical perspective. This approach to broadband is consistent with the concept of a broadband ecosystem introduced by Kelly and Raja (2010), in which broadband is a socially constructed artefact that is part of a cultural ecosystem. In a broadband context, STST addresses the social aspects of people and society, as well as the technical aspects of systems and technology. As a theoretical lens for broadband, STST enables the investigation of the technical subsystem (comprised of infrastructure, equipment, applications and service), the social subsystem (market, customers and industry), and the environment (regulation, policy and society) that are all critical components of a developing broadband society. Finding a common ground for the complex interrelationship of the three subsystems and industry above is the cracks of this research. The epistemological analysis of these determinants referred here to as subsystems should estab- 
lish the underlying, hidden layer of reality that informs the relationships among these. This approach is purely the socio-technical theory approach.

\subsubsection{Appropriateness of socio-technical approach} in this research. As already discussed, results of studies conducted in the recent past on broadband growth and penetration show the prevailing influence of GDP and economic development on the adoption of broadband. Studies of other possibly influencing variables have been inconclusive (Trkman et al., 2008). It is in these inconclusive studies that this research has its inspiration. The other influencing variables of broadband are societal in nature and require a socio-technical investigation to unearth their impact on broadband.

As opposed to the conventional economic model, the use of the socio-technical approach gives assurance that projects that are technological in nature give outcomes that are the result of a more complex interaction between technical and societal factors. "It is widely acknowledged that ICTs and the social and contextual settings in which they are embedded are in a relationship of reciprocal shaping" (Borgman, 2000). Given this assertion, this research intends to investigate the relationship between Technology, Society and Environment within the context of SADC. Some researchers have spoken of broadband influencing or changing the culture of societies, as Borgman (2002) says. This research argues that the shaping is reciprocal, therefore, society should speak to broadband as much as broadband speaks to society.

What is cardinal to note in the past studies that have emphasized the application of socio-technical systems theory to address the question of broadband growth and penetration is the fact that no real comprehensive and adaptive tool has been developed to help governments multinational companies to implement and monitor this approach. Especially tools that take cognizance of the context of a business setting with respect to societal differences brought about by variant backgrounds and histories of people groups. Even though this research preempts the importance of mutual shaping between technology and society, it is the researcher's submission that technology cannot and should not be placed at equal footing with societal values, therefore, in spite of how useful and advanced technology can be, its meant to serve society and not for society to serve it.

The prevailing broadband frameworks, not only in SADC, but also globally, largely lack the inclusion of societal uniqueness; culture, demographics, politics and much more, as indicated in the proposed framework, and how it relates to technology and its environment as an important part of the framework.

If the conventional economic framework model continues to be used uniformly in its current state among societies, we will not see much, if any, improvement in broadband growth and penetration, especially among developing economies. As a result, the digital divide and economic dichotomy between the first and the third world will persist.

Now that the application of STST to broadband growth and penetration has been qualified, the following section introduces the proposed socio-technical framework for broadband growth and penetration.

\section{The proposed conceptual framework}

The proposed framework for broadband growth and penetration is an open system comprised of two subsystems, Table 1 and Table 2.

The first part of the proposed framework is a decision making tool, Table 1. This decision making framework is four dimensional, as it relates broadband influencing factors, factors rank, type of intervention to be taken and the ration of the one intervention category to another.

Table 1. Decision-making broadband framework

\begin{tabular}{|c|c|c|c|c|}
\hline Interventions & Economic policy & Social policy & Weights or rankings & $\begin{array}{l}\text { Ratio of economic to social policy per } \\
\text { factor }\end{array}$ \\
\hline \multicolumn{5}{|l|}{ Society subsystem factors } \\
\hline \multicolumn{5}{|l|}{ Environment subsystem factors } \\
\hline \multicolumn{5}{|l|}{ Technology subsystem factors } \\
\hline Industry subsystem factors & & & & \\
\hline
\end{tabular}

Note: adapted from Telecommunications Policy (2008). 
While in the traditional business models the mindset has been that with state of the art technology high production and performance is guaranteed, the reality shows that this not necessarily so. The social aspect has to addressed as well and fully so. Hence, the results of the survey on factors affecting broadband growth and penetration revealed in which area do member states in SADC require to concentrate there intervention. The framework will also assist in approximating the ratio of business policy to social policy required for every factor identified.

Table 2 speaks to the complexities of the sociotechnical environment itself. The change from traditional models to the socio-technical approach comes with its own repercussions. Relationships are not automatically developed, support is needed continuously, knowledge of experts is not explicit, but tacit, meaning it only truly be transferred by spending time with the expert and many inherent properties of the socio-technical environment. Good leadership needs to preempt these challenges and prepare a contingent plan for solution. So, results of the survey will also inform the framework of policies that need to be in place to address these challenges.

Table 2 below is part of the proposed framework and it identifies possible attributes and repercussions prevalent in a socio-technical environment (Shin \& Jung, 2012). The purpose of the table is to relate the attributes and repercussions to preemptive policies that should address each of them. As already stated, the outcome of this research is this framework and the purpose for the framework is to help decision makers to implement policies that address the problem of broadband growth and penetration in SADC. It, therefore, follows that the table below can only become a tool if the policy column is filled and this can only be done using survey results.

Table 2. Socio-technical environment attributes and repercussion framework

\begin{tabular}{|l|l|l|l|}
\hline Attributes & Policy intervention & Repercussions & Policy intervention \\
\hline
\end{tabular}

Note: researcher's own.

Although the data for this research were gathered and analyzed, it is not within the scope of this paper to provide the SADC results. Only the framework used is dealt with in this paper.
In conclusion, according to Trist (1981), the environment and technology always changes. These changes necessitate redesigning of the sociotechnical environment. Therefore, the evolution of the socio-technical environment is unending and teams need to be always willing to redesign and adapt to the new environment, thus, the system should be strong enough to withstand and adapt to changes and fast to move with times.

The transcendental conditions of the researcher which are his faith commitment or spiritual directness will inevitably influence the way he sees and interprets the world (Van de Walt \& Potgieter, 2012). These convictions need to be started so as to give the reader a full picture of the work he/she is reading. The researcher here states that his work is viewed from a Christian perspective. This is the subconscious state of the researcher and, therefore, will unconsciously permeate his views and interpretations.

\section{Conclusion and recommendations}

In conclusion, the following points are worth that can be drawn from this research: broadband is an economic, as well as a social construction. It enables economic growth and societal upliftment. This is so, because nations with high broadband uptake have high GDP per capita and, when used positively, broadband makes human life easier. Measurement of broadband benefits is not direct, and broadband itself comes with complexities. The uptake of broadband is not only affected by economic factors, but also by societal uniqueness or social factors. As a result, STST better explains a broadband uptake model than just market forces. The socio-technical environment itself has inherent attributes and repercussions that purely require social policies to address them. Consultative research should always precede attempts to enhance broadband uptake. The proposed framework in this research can only be a useful decision making tool if people-specific data are first gathered to populate it. Therefore, the framework is general, but adaptive.

The following recommendations can be said of the research: a more targeted research can be done that addresses how the uniqueness of a people group can be quantitatively implemented at an organizational level. Another research worth considering would be a costing model for broadband growth with respect to its anticipated penetration.

\section{References}

1. Bauer, J., Gai, P., Kim, Y., Muth, T. \& Wildman, S. (2002). Foundations of Broadband Policy. 13th ITS Regional Conference.

2. Borgman, C. (2000). From Gutenberg to the Global Information Infrastructure: Access to Information in the Networked World. Cambridge, MA: MIT Press.

3. Broadband Commission. (2014). The state of broadband 2014: Broadband for all.

4. Burns, T. \& Stalker, G.M. (1961). The Management of Innovation. Tavistock, London. 
5. Chaudhuri, A. \& Flamm, K. (2004). Price, competition, and regulating the net. Presented at the Association of public policy analysis and management (APPAM) annual research conference, Atlanta, GA.

6. Checkland, P. \& Scholes, D. (1999). Soft systems methodology: a 30-year retrospective. Elsevier.

7. Cherns, A. (1976). The principles of socio-technical design, Human Relations, Vol. 29, pp. 783-792.

8. Cherns, A. (1986). Principles of socio-technical design revisited, Human Relations, Vol. 40, pp. 153-162.

9. Creswell, J.W. (2012). Educational research: planning, conducting, and evaluating qualitative research, 4th ed. Boston, MA: Pearson.

10. Cummings, T. (1981). Designing effective work groups. In Nystrom, P.C. and Starbuck, W.H. (Eds), Handbook of Organizational Design: Remodelling Organizations and Their Environments, Vol. 2. Oxford University Press, Oxford.

11. Cummings, T. (1994). Self-regulating work groups: a socio-technical synthesis. In French, Bell and Zawacki (Eds), Organizational Development and Transformation. 4th ed. Irwin Publishing, Burr Ridge, IL.

12. Cummings, T.G. \& Worley, C.G. (1993). Organizational Development and Change. 5th ed. West Publishing Co., Minneapolis, MN.

13. Duchek, S. (2013). Capturing Absorptive Capacity: A Critical Review and Future Prospects, Schmalenbach Business Review, Vol. 65, pp. 312-329.

14. Emery, R.E. and Trist, E.L. (1965). The causal texture of organizational environments, Human Relations, Vol. 18, pp. 21-32.

15. Firth, L. and Mellor, D. (2005). Broadband: Benefits and Problems, Telecommunications Policy, 29 (2-3), pp. $223-236$.

16. Flamm, K. and Chaudhuri, A. (2007). An analysis of the determinants of broadband access, Telecommunications Policy, 31 (6-7), pp. 312-326.

17. Frieden, R. (2005). Lessons from broadband development in Canada, Japan, Korea and the United States, Telecommunications Policy, 29, pp. 595-613.

18. GAO. (2000). U.S. General Accounting Office Report: Characteristics and choices of internet users [online]. Available at: http://www.gao.gov/new.items/d01345.pdf [accessed 23 April 2013].

19. Grayling, A.C. (2010). Thinking of answers. London, England: Bloomsbury.

20. Hackman, J.R. (1987). The design of work teams. In Lorsch, J.W. (Ed.), Handbook of Organizational Behavior. Prentice-Hall, Englewood Cliffs, NJ.

21. Hackman, R.J. \& Oldham, G.R. (1980). Work Redesign. Addison-Wesley, Reading, MA.

22. Harvey, D.F. \& Brown, R. (1992). An Experiential Approach to Organization Development. 4th ed. Prentice-Hall, Englewood Cliffs, NJ.

23. Hjørland, B. (2002). Principia Informatica. Foundational Theory of Information and Principles of Information Services, in Emerging Frameworks and Methods. Proceedings of the Fourth International Conference on Conceptions of Library and Information Science (CoLIS4), Greenwood Village, Colorado, USA: Libraries Unlimited, pp. 109-121.

24. Katz, J.E. \& Rice, R.E. (2007). Social Consequences of Internet Use: Access, Involvement, and Interaction [online]. Available at: http://rccs.usfca.edu/bookinfo.asp?BookID=372\&AuthorID=125 [accessed 13 January 2015].

25. Kelly, T. \& Raja, S. (2010). Building Broadband: Strategies and Policies for the Development. Global Information and Communication Technologies Department of World Bank [online]. Available at: http://siteresources.worldbank.org/EXTINFORMATIONANDCOMMUNICATIONANDTECHNOLOGIES/Reso urces/282822-1208273252769/Building_broadband.pdf [accessed 11 March 2014].

26. Luhmann, N. (1976). Profiles in Contemporary Social Theory. SAGE.

27. Mavetera, N. (2010). Philosophy of Social Science Research. In A. Mukoena and L. Makondo (eds), Fundamentals of Scientific Research and Publishing, Research and Publication Book Series, 1 (1), pp. 32-53.

28. Mugeni, G.B., Wanyembi, G.W. and Wafula, J.M. (2012). Evaluating Factors Affecting Broadband Intensity in Kenya, International Journal of Information and Communication Technology Research, 2 (10), pp. 769-778.

29. Olson, Jr. (1965). The Logic of Collective Action. Harvard University Press, 208 p.

30. Peck, S. (2006). The Road Less Travelled. Arrow Books.

31. Picot, A. \& Wernick, C. (2007). The role of government in broadband access [online]. Available at: www.elsevierbusinessandmanagement.com/locate/telpol [accessed 12 January 2014].

32. Picot, A. \& Wermick, C. (2007). The role of government in broadband access, Telecommunications Policy, 31 , pp. 660-674.

33. Qiang, C.Z.-W. \& Rossotto, C.M. (2009). Economic impacts of broadband, Information and Communications for Development 2009: Extending Reach and Increasing Impact, World Bank.

34. Sawyer, S., Allen, J.O. and Lee, H. (2003). Broadband and mobile opportunities: a socio-technical perspective, JBoruorandabla onfd I nafnodrm matoiobnil eT oepchpnorotluognyit i (eJsune 2003), 18, pp. 121-136.

35. Shin, D. \& Jung, J. (2012). Socio-technical analysis of Korea's broadband convergence network: Big plans, bigprojects, big prospects? Telecommunications Policy, 36, pp. 579-593 [online]. Available at: http://www.sciencedirect.com/science/article/pii/S0308596112000456 [accessed 20 March 2014].

36. The UCLA Internet report. (2000). The UCLA Internet report (2000). Surveying the digital future [online]. Available at: http://ccp.ucla.edu/UCLA-Internet-Report-2000.pdf [accessed 20 April 2011].

37. Trist, E. (1981). The evolution of socio-technical systems a conceptual framework and an action research program, Ontario Quality of Working Life Centre.

38. Trist, E., Higgin, B., Murray, J. \& Pollack, A. (1963). Organizational Choice. Tavistock, London. 
39. Trkman, P., Blazic, B.J. \& Turk, T. (2008). Factors of broadband development and the design of a strategic policy framework, Telecommunications Policy, 32, pp. 101-115 [online]. Available at: www.elsevierbusinessandmanagement.com/locate/telpol [accessed 22 March 2014].

40. World Bank Group. (2009). Information and Communications for Development [online]. Available at: https://www.google.co.za/?gws_rd=ssl\#q=Information+and+Communications+for+Development\%2C+The+world +Bank [accessed 11 March 2012].

41. World Bank Group. (2014). Broadband Strategies Toolkit [online]. Available at: http://broadbandtoolkit.org/0 [accessed 12 September 2013]. 